AperTO - Archivio Istituzionale Open Access dell'Università di Torino

Biochemical features of dye-decolorizing peroxidases: Current impact on lignin degradation

This is a pre print version of the following article:

Original Citation:

Availability:

This version is available http://hdl.handle.net/2318/1807922

since 2021-09-30T20:51:46Z

Published version:

DOI:10.1002/bab.2015

Terms of use:

Open Access

Anyone can freely access the full text of works made available as "Open Access". Works made available under a Creative Commons license can be used according to the terms and conditions of said license. Use of all other works requires consent of the right holder (author or publisher) if not exempted from copyright protection by the applicable law. 


\title{
Biochemical features of Dye-decolorizing peroxidases: current impact on lignin degradation
}

\author{
Gianluca Catucci, Francesca Valetti, Sheila J. Sadeghi and Gianfranco Gilardi* \\ Department of Life Sciences and Systems Biology, University of Torino, Italy
}

* Corresponding author: Department of Life Sciences and Systems Biology, Via Accademia Albertina 13, 10123 Torino, Italy.

E-mail address: gianfranco.gilardi@unito.it 


\section{Abstract}

Dye-decolorizing peroxidases (DyP) were originally discovered in fungi for their ability to decolorize several different industrial dyes. DyPs catalyze the oxidation of a variety of substrates such as phenolic and non-phenolic aromatic compounds. Catalysis occurs in the active site or on the surface of the enzyme depending on the size of the substrate and on the existence of radical transfer pathways available in the enzyme. DyPs show the typical features of heme containing enzymes with a Soret peak at 404-408 $\mathrm{nm}$. They bind hydrogen peroxide that leads to the formation of the so-called Compound I, the key intermediate for catalysis. This then decays into Compound II yielding back $\mathrm{Fe}(\mathrm{III})$ at its resting state. Each catalytic cycle uses two electrons from suitable electron donors and generates two product molecules.

DyPs are classified as a separate class of peroxidases. As all peroxidases they encompass a conserved histidine that acts as the fifth heme ligand, however all primary DyP sequences contain a conserved GxxDG motif and a distal arginine that is their characteristic. Given their ability to attack monomeric and dimeric lignin model compounds as well as polymeric lignocellulose, DyPs are a promising class of biocatalysts for lignin degradation that not only represents a source of valuable fine-chemicals, but it also constitutes a fundamental step in biofuels production. Research efforts are envisioned for the improvement of the activity of DyPs against lignin, through directed evolution, ration protein design or one-pot combination with other enzymes to reach satisfactory conversion levels for industrial applications. 


\section{Introduction}

Every year the global demand for energy increases. World energy consumption will rise $50 \%$ between 2018 and 2050 reaching a total consumption of 911 quadrillion British thermal units (Btu) in 2050. As a consequence, the use of renewable energy sources has become a key strategy to avoid increased greenhouse emissions. Projections for 2050 indicate that renewable energies will become the leading source of primary energy consumption accounting for $250 \mathrm{Btu}$ [1] (Figure 1). Biomasses are the primary source of renewable energy that can be exploited for the production of chemicals and fuels [2, 3]. Plants are widely distributed and their biomass can be transformed to produce liquid biofuels such as bioethanol, biodiesel or biobutanol [4]. First generation biofuels typically derive from corn, palm oil or sugarcane that are extracted from plants to obtain raw materials [5]. These biomasses have been extensively used worldwide thanks to well established technologies. Nevertheless, first generation biofuels are limited by the fact that the amount of carbon that is recovered throughout the process does not exceed the amount that feedstocks release during the production. Moreover, global increasing demand of biomass-derived biofuels [6] can shift the production from food crops to biofuels crops posing both macroeconomics and ethics questions of "fuel versus food" [7]. For this reason, lignocellulosic material could be a better substrate for biofuels production. Production of lignocellulose is $200 \times 10^{9}$ tons per year [8] and its cost is approximately $50 \%$ lower than other feedstock. Lignocellulose is the most abundant and least used resource of fuels and raw materials [9]. Plant cell walls are a primary source of lignocellulosic material that is made of cellulose, hemicellulose, lignin and other components like organic acids, tannins and proteins [10]. The chemical structure of lignocellulosic material cannot be predicted accurately [2] and it can be deeply influenced by growth, storage and harvest conditions. While hemicellulose and cellulose have a more regular structure characterized by the repetitions of the sugar units lignin 
is characterized by a complex aromatic structure that is harder to attack and has been considered a low-value product by most bio-rafineries [2]. The cross-linking of lignin is obtained via oxidative coupling of the various small units such as: synaptyl, coniferyl and p-coumaryl alcohols [11]. Given the structure of these compounds, lignin potentially is an excellent source of fine chemicals and its valorization can be obtained through a deconstruction process [12] leading to the breakage of carbon-oxygen and carbon-carbon bonds in its complex structure. This is a task that can be done by powerful tools such as enzymes that are commonly available in small microorganisms. A white rot fungus, Phanerochaete chrysosporium is the best studied organism for lignin degradation [13]. The microorganism synthetizes and secretes a set of lignin peroxidases isozymes that are able to attack lignin [14-16] through a radical transfer mechanism [17, 18]. Lignin peroxidases [19], can oxidize a variety of different phenolic aromatic compounds as well as non-phenolic lignin model compounds [20]. They are characterized by the presence of two $\mathrm{Ca}^{2+}$ binding sites, two glycosylation sites and four disulfide bridges that stabilize the structure of the enzyme [21]. Their molecular weight ranges between 35 and $48 \mathrm{kDa}$ and the isoelectric point between 3.1 and 4.8 [21].

Peroxidases were also used as model systems to understand the interaction between proteins and electrodes using mediators to shuttle electrons between the working electrode and the enzyme $[22,23]$. Ferrocene mediators (negatevely charged, positevely charged and neutral) were found to be able to interact with Cytochrome c Peroxidase (CcP) in different ways due to the presence of a cluster of negative amino acids on the surface of the enzyme that interact better with opposite (positive) charges [22]. Further characterization of the system performing site directed mutagenesis of a single amino acid on the surface of CcP, Asp34Lys, resulted in a faster electron transfer confirming the importance of optimizing surface chemistry interaction $[23,24]$. 
Previous reports have highlighted a role of several different classes of enzymes in attacking lignin or lignin model compounds. Lignin peroxidases [25-28], manganese-dependent peroxidases [29-31], versatile peroxidases [32] and laccases [13, 33-36], have been extensively studied for their lignin degradation activity. These enzymes, except for laccases, all depend on $\mathrm{H}_{2} \mathrm{O}_{2}$ for their activity. Interestingly recent works highlight the importance of $\mathrm{H}_{2} \mathrm{O}_{2}$ to drive the catalytic cycles of other class of enzymes. Among them, cytochrome P450 peroxygenases are very promising candidates to be exploited for the production of biofuels as they are able to react with $\mathrm{H}_{2} \mathrm{O}_{2}$ to generate catalytically competent heme iron-oxo species [3739]. Moreover cytochromes $P 450$ were found to be a valuable catalysts for lignin bioconversion [40]. Cytochromes P450 are known to be extremely powerful catalysts with broad substrate specificity $[41,42]$ that can be exploited for pharmaceutical, environmental and bionsensing applications [43], but except for the peroxygenase subgroup, their activity relies in the proper shuttling, coupling and optimization of electrons from a reductase partner [44, 45]. This review focusses on the structure/function relationship of a new family of peroxidases, named dyedecolorizing peroxidases, that have demonstrated a role in lignin breakdown [46], through the use hydrogen peroxide as co-substrate and high potential for biotechnological applications thanks to their presence in bacterial genomes $[47,48]$ that facilitates heterologous production in E.coli.

\section{Dye-decolorizing peroxidases}

DyP peroxidases were first discovered in fungi in 1995 when the basidiomycete Geotrichum candidum (G. candidum) was found to be able to decolorize several different dyes [49]. A few years later, in 1999, the enzyme from G. candidum responsible for the decolorization reaction was purified [50] and upon characterization it showed the typical features of a heme containing 
enzyme with a Soret peak at $406 \mathrm{~nm}$ [50]. Bioinformatics analysis revealed that DyP peroxidases belong to a separate class of enzymes as they do not share sequence homology or structure with other known peroxidases [51]. For an outline of the characteristics of DyP from T.cucumeris (formerly G. candidum) and an in-depth analysis of the DyP-type peroxidase family please refer to Sugano 2009 [52].

The range of industrial dyes attacked by DyPs is very wide [50], particularly those derived from anthraquinone. DyPs are classified as peroxidases (EC 1.11.1) with EC number 1.11.1.19. Initially they were thought to be only of fungal origins, but now they also have been found in the genome of bacteria and archea $[48,51]$. Analysis of their role in these organisms highlighted how these enzymes can have both oxidative and hydrolytic activity [51]. Today it can be stated that DyP peroxidases constitute a microbial super family of heme peroxidase not present in plants or animals [51] and their physiological role in bacteria and fungi is not yet clear. Substrates tested include a variety of aromatic compounds classified as dyes [50, 53-56], betacarotene [57], aromatic sulfides [48], some of which are poorly metabolized by other heme peroxidases. Numerous studies have shown that DyP peroxidases play a key role in the degradation of lignin [54, 55, 58-65]. Their catalytic properties make them very interesting because the bacterial enzymes can be easily engineered, heterologously expressed in E.coli and purified [65] avoiding the issues of using an eukaryotic hosts.

DyP peroxidases are classified in four subclasses: A, B, C, D [51]. All Dyps possess a Type b non covalently bound heme. Most bacterial DyPs, are cytoplasmic enzymes and belong to the subclasses $B$ and $C$. The DyPs belonging to the subclass $A$, present a signal sequence called "Tat-signal", responsible for their export to the extracellular environment [66, 67]. Subclass D mainly contains enzymes of a fungal nature that are secreted outside the cell $[51,68]$. 


\section{Structural features and catalytic cycle}

While the most widely used classification of DyP is purely sequence-based Yoshida and Sugano in 2015 have proposed a new classification that is based on the tertiary structure of the DyPs [68]. In the new classification Class $P$ replaces former Class $B$; former Classes $A$ becomes Class I, former Classes C and D are joined in Class V. P indicates "primitive", I stands for "intermediate" and V represents "advanced". The new division into 3 Classes highlights: 1) the common structural features shared by Class $C$ and $D$ in the same structure regions reflected also by their higher catalytic efficiencies of their members; 2 ) the fact that class A proteins have the extra sequences fewer than those of class $V$ and 3 ) the uniqueness of Class $P$ displaying a more overall compact structure.

In terms of the the primary sequence DyP peroxidases contain a conserved histidine that acts as the fifth heme ligand, a conserved GxxDG motif and a distal arginine [52]. As expected, in general mutation of the histidine to an alanine results in the loss of the heme and complete inactivation of the enzyme [48]. Within the GxxDG motif, aspartate plays an important role by performing deprotonation of $\mathrm{H}_{2} \mathrm{O}_{2}$ that is crucial for Compound I formation [69]. Nevertheless, it has been found that, in DypB from Rhodococcus jostii RHA1, the conserved aspartate is not required for peroxidase activity and replacement of this residue by alanine only marginally affects the reactivity towards $\mathrm{H}_{2} \mathrm{O}_{2}$ and the formation of compound I [70]. Furthermore, the dyedecolorizing peroxidase EfeB/YcdB from E.coli was found to maintain its activity even when Asp 235 is mutated to asparagine suggesting that EfeB is a unique DyP protein member [71]. It follows that the specific role of aspartate can show some variability in some specific enzymes and the matter remains under question. 
The conserved arginine in the active site was also studied. The role of this residue seems to be structural as its mutation compromises the architecture of its distal heme cavity and access channel [72].

The molecular weight of monomeric DyP is between 35-60 kDa. However these enzymes have been shown to exist in different states: monomeric $[50,69,73]$, to dimeric $[57,71,74,75]$, tetrameric [76] and hexameric [75]. The various enzymes belonging to the different classes of DyPs highlight how these enzymes do not have a high degree of sequence homology [47]. From the structural point of view, on the other hand, these enzymes show a highly conserved topology [47]. All DyPs have two alpha and beta domains that are organized in a ferrodoxintype folding structure, consisting of four beta anti-parallel sheets surrounded by alpha helices [47]. The two domains, alpha and beta, form the active site cavity that hosts heme. To date, 39 crystal structures of DyPs are known (Table 1) [64, 70, 71, 72, 75, 77-90].

Detailed studies of the catalytic cycle show that hydrogen peroxide deprotonation is the first step (Figure 2). This step requires the presence of an amino acid that works as a base yielding a $\mathrm{Fe}(\mathrm{III})-\mathrm{OOH}$ complex that is normally called Compound 0 . This reaction is very fast and therefore it is hard to experimentally catch the reaction intermediate. At this point heterolytic cleavage of the $\mathrm{O}-\mathrm{O}$ can occur leading to the formation of the $\mathrm{Fe}(\mathrm{IV})-\mathrm{O}$ porphyrin radical Compound I. The formation of Compound II (FelV-OH) from Compound I is achieved through a 1-electron reduction producing a first radical species [72]. Finally, the ferric Iron resting state (FellI) is regenerated by a second 1-electron reduction with generation of a second radical [72]. An earlier shunt of the catalytic cycle is also possible through immediate 2-electron reduction of Compound I generating ferric Iron resting state (FellI). 


\section{Long range electron transfer}

DyPs are able to catalyze the oxidation of substrates that due to their large size are not able to enter the active site of the enzyme [80]. For this reason electron transfer must occur from the active site to the surface of the enzyme via a long range electron transfer pathway. The best candidates to perform catalysis at the surface of the enzyme are typically tryptophan and tyrosine residues [80]. These amino acids can form stable radicals that participate directly to charge transfer. Site directed mutagenesis followed by EPR spectroscopy gave evidenced different abilities of the enzyme to generate radical species. Cross-linking experiments, where enzymes are incubated with hydrogen peroxide at different $\mathrm{pH}$ to test the possibility of forming covalent dimers by SDS-Page, allowed the identification of the specific surface residues involved. Shrestha et al. reported the involvement of W263 in substrate oxidation in a class A DyP from Thermomonospora curvata [77]. Mutation of the tryptophan resulted in $50 \%$ loss of activity and sigmoidal kinetics for Reactive Blue 19 dye (RB19) as substrate. On the contrary, the same authors found also that Trp336 is an off-pathway electron transfer destination of the enzyme and that mutation of this residue improves the stability of compound I and avoids covalent cross-linking of enzymatic units in the absence of substrate [77].

A class B DyP peroxidase from Vibro Cholerae was characterized for its ability to perform substrate oxidation at the enzyme surface. Interestingly, in Vibro cholerae two tyrosine couples are responsible for enzyme covalent cross-linking (Y109 and Y133) and enzymatic activity respectively (Tyr129 and Tyr235 Figure 3A) [80]. Moreover, while radical formation occurs at every $\mathrm{pH}$, substrate oxidation occurs at lower $\mathrm{pH}$ and cross-linking is observed mainly at higher $\mathrm{pH}$. Therefore the authors have hypothesized the presence of a $\mathrm{pH}$ dependent switch in the radical transfer pathway controlled by $\mathrm{H} 178$ that forms a hydrogen bond with $\mathrm{Thr} 277$ and drives conformational change in a $\mathrm{pH}$ dependent manner [80]. In order to understand if this pathway 
is conserved in other DyPs we have performed a three dimensional structural alignment of Vibrio Cholerae DyP with other members of the same class and the overlay shows that at least one of the two productive pathways is probably present exploiting the conserved His 178 and Tyr235 (Figure 3B).

For class D DyP peroxidases Tyr337 and Leu357 were reported to be involved in the radical transfer patwhay of AauDyPI to the surface [91] [88].

\section{Lignin degradation}

Over the last 20 years, many different dye-decolorizing peroxidases have been biochemically characterized. This is usually achieved by first identifying a strain that shows activity against a lignocellulose matrix, then isolating the enzyme that is responsible for lignin degradation. Given the complex structure of lignin, once the enzymatic target is expressed and purified in a suitable host, different options are available to evaluate the activity of the enzyme. A bottom-up approach consists in testing a variety of monomer compounds that represent a specific class, for instance phenolic or non-phenolic compounds. A second level of complication entails the testing of the activity of the enzyme against one or more dimeric lignin model compounds. Further analysis requires the assessment of enzymatic activity against either wheat straw lignocellulose, nitrated lignin, kraft lignin or organosolv lignin (Figure 4A). Recently, a rapid and economic colorimetric assay, based on the reaction of 2,4-dinitrophenylhydrazine with the carbonyl product of the enzyme for lignin oxidation was reported. This allows a simple oxidative screening of enzymes involved in lignin degradation [92] accelerating the initial phase of the characterization process (Figure 4B). Indeed, dye-decolorizing peroxidases very often demonstrate activity against phenolic compounds, but they do not always accept non-phenolic compounds or more complicated lignin molecules. New sources of bacterial or fungal dye- 
decolorizing peroxidases active on polymerized lignin have become available from a variety of organisms [46, 53, 64, 93-95]. The jelly fungus Auricularia auricular-judae Dyp peroxidases AjP I and AjP || were found to be active on aldlerol, a non phenolic beta-O-4 lignin model dimer exhibiting maximum activity at $\mathrm{pH} 1.4$ [53]. AjP I resulted more stable than AjP II and upon incubation at at $\mathrm{pH} 2.5$ did not lose activity over a time span of 4 hours [53]. DypB from Rhodococcus jostii RHA1 was tested against pinoresinol and three different beta-aryl ether model compounds: a p-hydroxy analogue, a guaiacyl analogue and a syringyl analogue. Guaiacyl beta-aryl ether was gradually consumed in time with specific activity for the erythro and threo isomers of $0.017 \mathrm{micromol} / \mathrm{min}$ and $0.005 \mathrm{micromol} / \mathrm{min}$ respectively [46]. DypB from Rhodococcus was also able to attack wheat straw lignocellulose or kraft lignin in the presence of $\mathrm{MnCl}_{2}$ [46]. DypA and Dyp1B from Pseudomonas fluorescens exhibited Michaelis-Menten like kinetic behavior upon incubation with kraft Lignin whereas in the presence of $\mathrm{Mn}$ (II) only Dyp1B showed activity against wheat straw lignocellulose yielding a lignin fragment containing two aryl-C3 units [93]. Reactivity against kraft lignin was also reported for a Dyp peroxidase from Thermobifida fusca [64]. The enzyme showed the conversion of guaiacylglycerol-betaguaiacyl ether to corresponding beta-aryl monomer as a consequence of the oxidative dimerization of the model compound [64].

\section{Conclusion}

DyP peroxidases are biocatalysts with great potential in second generation biofuel production. The data available in literature point towards a primary role of DyPs in the degradation of lignin, a complex matrix that contains highly polymerized molecules with variable structure, which cannot be easily attacked by a single enzyme. Nevertheless, it should be mentioned that lignin degradation activities of DyPs are low when compared with those of lignin peroxidases and 
manganese peroxidases [96]. Future works should aim at directed evolution of DyPs to improve their catalytic activity and testing the combination of DyP peroxidases and other lignin degrading or modifying enzymes to perform a more radical and effective transformation of lignin matrix. The combination of a multi-enzyme approach will yield a fraction of low molecular mass aromatic compounds that can be easily adopted by the industry as starting raw materials. Furthermore, rational design efforts will also be beneficial for DyP peroxidases. Recent work showed how adjustment of bacterial growth combined with protein engineering allows protein overexpression at yields $>100 \mathrm{mg} / \mathrm{L}$ [65]. Future work should also be aimed at improving the activity of the enzymes at higher $\mathrm{pH}$ because the acidic conditions can limit their application [97].

\section{Acknowledgements}

Two images were Created with BioRender.com.

\section{Conflict of interest}

None

\section{References}

1. International Energy Outlook 2019.

2. Bugg, T.D.,Rahmanpour, R. (2015) Enzymatic conversion of lignin into renewable chemicals. Current Opinion in Chemical Biology, 29, 10-17.

3. Vennestrøm, P.N.R., Osmundsen, C.M., Christensen, C.H.,Taarning, E. (2011) Beyond Petrochemicals: The Renewable Chemicals Industry. Angew. Chem. Int. Ed., 50 (45), 10502-10509.

4. (2011) Biofuels, Elsevier.

5. Aro, E.-M. (2016) From first generation biofuels to advanced solar biofuels. Ambio, 45 (S1), 24-31.

6. Popp, J., Lakner, Z., Harangi-Rákos, M.,Fári, M. (2014) The effect of bioenergy expansion: Food, energy, and environment. Renewable and Sustainable Energy Reviews, 32, 559-578.

7. Lee, R.A.,Lavoie, J.-M. (2013) From first- to third-generation biofuels: Challenges of producing a commodity from a biomass of increasing complexity. Animal Frontiers, 3 (2), 6-11.

8. De Bhowmick, G., Sarmah, A.K.,Sen, R. (2018) Lignocellulosic biorefinery as a model for sustainable development of biofuels and value added products. Bioresource Technology, 247, 1144-1154.

9. Chen, H. (2013) Modern solid state fermentation theory and practice, Springer, Dordrecht.

10. Welker, C., Balasubramanian, V., Petti, C., Rai, K., DeBolt, S.,Mendu, V. (2015) Engineering Plant Biomass Lignin Content and Composition for Biofuels and Bioproducts. Energies, 8 (8), 7654-7676.

11. Pollegioni, L., Tonin, F., Rosini, E. (2015) Lignin-degrading enzymes. FEBS J., 282 (7), 1190-1213. 
12. Lee, S., Kang, M., Bae, J.-H., Sohn, J.-H.,Sung, B.H. (2019) Bacterial Valorization of Lignin: Strains, Enzymes, Conversion Pathways, Biosensors, and Perspectives. Front. Bioeng. Biotechnol., 7, 209.

13. Janusz, G., Kucharzyk, K.H., Pawlik, A., Staszczak, M.,Paszczynski, A.J. (2013) Fungal laccase, manganese peroxidase and lignin peroxidase: gene expression and regulation. Enzyme Microb. Technol., 52 (1), 1-12.

14. Tien, M.,Kirk, T.K. (1983) Lignin-Degrading Enzyme from the Hymenomycete Phanerochaete chrysosporium Burds. Science, 221 (4611), 661-663.

15. Paszczyński, A., Huynh, V.B.,Crawford, R. (1986) Comparison of ligninase-I and peroxidase-M2 from the white-rot fungus Phanerochaete chrysosporium. Arch. Biochem. Biophys., 244 (2), 750-765.

16. Kirk, T.K.,Farrell, R.L. (1987) Enzymatic «combustion»: the microbial degradation of lignin. Annu. Rev. Microbiol., 41, 465-505.

17. Gilardi, G., Harvey, P.J., Cass, A.E.G.,Palmer, J.M. (1990) Radical intermediates in veratryl alcohol oxidation by ligninase. NMR evidence. Biochimica et Biophysica Acta (BBA) - Protein Structure and Molecular Enzymology, 1041 (2), 129-132.

18. Harvey, P.J., Gilardi, G.-F., Goble, M.L.,Palmer, J.M. (1993) Charge transfer reactions and feedback control of lignin peroxidase by phenolic compounds: Significance in lignin degradation. Journal of Biotechnology, $\mathbf{3 0}$ (1), 57-69.

19. Edwards, S.L., Raag, R., Wariishi, H., Gold, M.H.,Poulos, T.L. (1993) Crystal structure of lignin peroxidase. Proc. Natl. Acad. Sci. U.S.A., 90 (2), 750-754.

20. Wong, D.W.S. (2009) Structure and action mechanism of ligninolytic enzymes. Appl. Biochem. Biotechnol., 157 (2), 174-209.

21. Janusz, G., Pawlik, A., Sulej, J., Świderska-Burek, U., Jarosz-Wilkołazka, A.,Paszczyński, A. (2017) Lignin degradation: microorganisms, enzymes involved, genomes analysis and evolution. FEMS Microbiology Reviews, 41 (6), 941-962.

22. Sadeghi, S.J.,Cass, A.E. (1995) Electron transfer between cytochrome C peroxidase and ferrocene. Biochem. Soc. Trans., 23 (2), 153S.

23. Sadeghi, S.J., Gilardi, G.,Cass, A.E. (1997) Mediated electrochemistry of peroxidases--effects of variations in protein and mediator structures. Biosens Bioelectron, 12 (12), 1191-1198.

24. Sadeghi, S.J., Gilardi, G., Nicolosi, G.,Cass, A.E.G. (1997) Chiral discrimination in the oxidation of ferrocenes by cytochrome c peroxidase. Chem. Commun., (6), 517-518.

25. Chan, J.C., Paice, M.,Zhang, X. (2020) Enzymatic Oxidation of Lignin: Challenges and Barriers Toward Practical Applications. ChemCatChem, 12 (2), 401-425.

26. Pérez, J., Muñoz-Dorado, J., de la Rubia, T.,Martínez, J. (2002) Biodegradation and biological treatments of cellulose, hemicellulose and lignin: an overview. Int. Microbiol., 5 (2), 53-63.

27. Valli, K., Wariishi, H.,Gold, M.H. (1990) Oxidation of monomethoxylated aromatic compounds by lignin peroxidase: role of veratryl alcohol in lignin biodegradation. Biochemistry, 29 (37), 8535-8539.

28. Falade, A.O., Nwodo, U.U., Iweriebor, B.C., Green, E., Mabinya, L.V.,Okoh, A.I. (2017) Lignin peroxidase functionalities and prospective applications. MicrobiologyOpen, 6 (1), e00394.

29. Chowdhary, P., Shukla, G., Raj, G., Ferreira, L.F.R.,Bharagava, R.N. (2019) Microbial manganese peroxidase: a ligninolytic enzyme and its ample opportunities in research. SN Appl. Sci., 1 (1), 45.

30. Hatakka, A., Lundell, T., Hofrichter, M.,Maijala, P. (2003) Manganese Peroxidase and Its Role in the Degradation of Wood Lignin, in Applications of Enzymes to Lignocellulosics, vol. 855, American Chemical Society, Washington, DC, pagg. 230-243.

31. Gold, M.H., Youngs, H.L.,Gelpke, M.D. (2000) Manganese peroxidase. Met lons Biol Syst, 37, 559-586.

32. Ravichandran, A.,Sridhar, M. (2017) Insights into the Mechanism of Lignocellulose Degradation by Versatile Peroxidases. Current Science, 113 (01), 35.

33. Liu, Y., Luo, G., Ngo, H.H., Guo, W.,Zhang, S. (2020) Advances in thermostable laccase and its current application in lignin-first biorefinery: A review. Bioresour. Technol., 298, 122511.

34. Wang, J., Feng, J., Jia, W., Chang, S., Li, S.,Li, Y. (2015) Lignin engineering through laccase modification: a promising field for energy plant improvement. Biotechnol Biofuels, 8, 145. 
35. Becker, J.,Wittmann, C. (2019) A field of dreams: Lignin valorization into chemicals, materials, fuels, and health-care products. Biotechnology Advances, 37 (6), 107360.

36. Shin, S.K., Ko, Y.J., Hyeon, J.E.,Han, S.O. (2019) Studies of advanced lignin valorization based on various types of lignolytic enzymes and microbes. Bioresource Technology, 289, 121728.

37. Munro, A.W., McLean, K.J., Grant, J.L.,Makris, T.M. (2018) Structure and function of the cytochrome P450 peroxygenase enzymes. Biochem. Soc. Trans., 46 (1), 183-196.

38. Ciaramella, A., Catucci, G., Gilardi, G.,Di Nardo, G. (2019) Crystal structure of bacterial CYP116B5 heme domain: New insights on class VII P450s structural flexibility and peroxygenase activity. Int. J. Biol. Macromol., 140, 577-587.

39. Ciaramella, A., Catucci, G., Di Nardo, G., Sadeghi, S.J.,Gilardi, G. (2020) Peroxide-driven catalysis of the heme domain of $A$. radioresistens cytochrome $\mathrm{P} 450116 \mathrm{~B} 5$ for sustainable aromatic rings oxidation and drug metabolites production. $N$ Biotechnol, 54, 71-79.

40. Mallinson, S.J.B., Machovina, M.M., Silveira, R.L., Garcia-Borràs, M., Gallup, N., Johnson, C.W., Allen, M.D., Skaf, M.S., Crowley, M.F., Neidle, E.L., Houk, K.N., Beckham, G.T., DuBois, J.L.,McGeehan, J.E. (2018) A promiscuous cytochrome P450 aromatic O-demethylase for lignin bioconversion. Nat Commun, 9 (1), 2487.

41. Isin, E.M.,Guengerich, F.P. (2007) Complex reactions catalyzed by cytochrome P450 enzymes. Biochimica et Biophysica Acta (BBA) - General Subjects, 1770 (3), 314-329.

42. Bernhardt, R. (2006) Cytochromes P450 as versatile biocatalysts. Journal of Biotechnology, 124 (1), $128-145$.

43. Ferrero, V.E.V., Di Nardo, G., Catucci, G., Sadeghi, S.J.,Gilardi, G. (2012) Fluorescence detection of ligand binding to labeled cytochrome P450BM3. Dalton Trans., 41 (7), 2018-2025.

44. Degregorio, D., D’Avino, S., Castrignanò, S., Di Nardo, G., Sadeghi, S.J., Catucci, G.,Gilardi, G. (2017) Human Cytochrome P450 3A4 as a Biocatalyst: Effects of the Engineered Linker in Modulation of Coupling Efficiency in 3A4-BMR Chimeras. Front. Pharmacol., 8.

45. Castrignanò, S., D’Avino, S., Di Nardo, G., Catucci, G., Sadeghi, S.J.,Gilardi, G. (2018) Modulation of the interaction between human P450 3A4 and B. megaterium reductase via engineered loops. Biochimica et Biophysica Acta (BBA) - Proteins and Proteomics, 1866 (1), 116-125.

46. Ahmad, M., Roberts, J.N., Hardiman, E.M., Singh, R., Eltis, L.D.,Bugg, T.D.H. (2011) Identification of DypB from Rhodococcus jostii RHA1 as a Lignin Peroxidase. Biochemistry, 50 (23), 5096-5107.

47. Colpa, D.I., Fraaije, M.W.,van Bloois, E. (2014) DyP-type peroxidases: a promising and versatile class of enzymes. J Ind Microbiol Biotechnol, 41 (1), 1-7.

48. van Bloois, E., Torres Pazmiño, D.E., Winter, R.T.,Fraaije, M.W. (2010) A robust and extracellular hemecontaining peroxidase from Thermobifida fusca as prototype of a bacterial peroxidase superfamily. Appl. Microbiol. Biotechnol., 86 (5), 1419-1430.

49. Kim, S.J., Ishikawa, K., Hirai, M.,Shoda, M. (1995) Characteristics of a newly isolated fungus, Geotrichum candidum Dec 1, which decolorizes various dyes. Journal of Fermentation and Bioengineering, 79 (6), 601607.

50. Kim, S.J.,Shoda, M. (1999) Purification and characterization of a novel peroxidase from Geotrichum candidum dec 1 involved in decolorization of dyes. Appl. Environ. Microbiol., 65 (3), 1029-1035.

51. Savelli, B., Li, Q., Webber, M., Jemmat, A.M., Robitaille, A., Zamocky, M., Mathé, C.,Dunand, C. (2019) RedoxiBase: A database for ROS homeostasis regulated proteins. Redox Biol, 26, 101247.

52. Sugano, Y. (2009) DyP-type peroxidases comprise a novel heme peroxidase family. Cell. Mol. Life Sci., 66 (8), 1387-1403.

53. Liers, C., Bobeth, C., Pecyna, M., Ullrich, R.,Hofrichter, M. (2010) DyP-like peroxidases of the jelly fungus Auricularia auricula-judae oxidize nonphenolic lignin model compounds and high-redox potential dyes. Appl Microbiol Biotechnol, 85 (6), 1869-1879.

54. Yang, J., Gao, T., Zhang, Y., Wang, S., Li, H., Li, S.,Wang, S. (2019) Degradation of the phenolic $\beta$-ether lignin model dimer and dyes by dye-decolorizing peroxidase from Bacillus amyloliquefaciens. Biotechnol Lett, 41 (8-9), 1015-1021. 
55. Min, K., Gong, G., Woo, H.M., Kim, Y.,Um, Y. (2015) A dye-decolorizing peroxidase from Bacillus subtilis exhibiting substrate-dependent optimum temperature for dyes and $\beta$-ether lignin dimer. Sci Rep, $\mathbf{5}$ (1), 8245.

56. Amara, S., Perrot, T., Navarro, D., Deroy, A., Benkhelfallah, A., Chalak, A., Daou, M., Chevret, D., Faulds, C.B., Berrin, J.-G., Morel-Rouhier, M., Gelhaye, E.,Record, E. (2018) Enzyme Activities of Two Recombinant HemeContaining Peroxidases, TV DyP1 and TV VP2, Identified from the Secretome of Trametes versicolor. Appl Environ Microbiol, 84 (8), e02826-17, /aem/84/8/e02826-17.atom.

57. Scheibner, M., Hülsdau, B., Zelena, K., Nimtz, M., de Boer, L., Berger, R.G.,Zorn, H. (2008) Novel peroxidases of Marasmius scorodonius degrade beta-carotene. Appl. Microbiol. Biotechnol., 77 (6), 1241-1250.

58. Brown, M.E., Barros, T.,Chang, M.C.Y. (2012) Identification and Characterization of a Multifunctional Dye Peroxidase from a Lignin-Reactive Bacterium. ACS Chem. Biol., 7 (12), 2074-2081.

59. Chen, C., Shrestha, R., Jia, K., Gao, P.F., Geisbrecht, B.V., Bossmann, S.H., Shi, J.,Li, P. (2015) Characterization of Dye-decolorizing Peroxidase (DyP) from Thermomonospora curvata Reveals Unique Catalytic Properties of A-type DyPs. J. Biol. Chem., 290 (38), 23447-23463.

60. Duan, Z., Shen, R., Liu, B., Yao, M.,Jia, R. (2018) Comprehensive investigation of a dye-decolorizing peroxidase and a manganese peroxidase from Irpex lacteus F17, a lignin-degrading basidiomycete. $A M B$ Expr, 8 (1), 119.

61. Lin, L., Wang, X., Cao, L.,Xu, M. (2019) Lignin catabolic pathways reveal unique characteristics of dyedecolorizing peroxidases in Pseudomonas putida. Environ Microbiol, 21 (5), 1847-1863.

62. Qin, X., Luo, H., Zhang, X., Yao, B., Ma, F.,Su, X. (2018) Dye-decolorizing peroxidases in Irpex lacteus combining the catalytic properties of heme peroxidases and laccase play important roles in ligninolytic system. Biotechnol Biofuels, 11 (1), 302.

63. Rahman Pour, R., Ehibhatiomhan, A., Huang, Y., Ashley, B., Rashid, G.M., Mendel-Williams, S.,Bugg, T.D.H. (2019) Protein engineering of Pseudomonas fluorescens peroxidase Dyp1B for oxidation of phenolic and polymeric lignin substrates. Enzyme and Microbial Technology, 123, 21-29.

64. Rahmanpour, R., Rea, D., Jamshidi, S., Fülöp, V.,Bugg, T.D.H. (2016) Structure of Thermobifida fusca DyPtype peroxidase and activity towards Kraft lignin and lignin model compounds. Archives of Biochemistry and Biophysics, 594, 54-60.

65. Vignali, E., Tonin, F., Pollegioni, L.,Rosini, E. (2018) Characterization and use of a bacterial lignin peroxidase with an improved manganese-oxidative activity. Appl Microbiol Biotechnol, 102 (24), 10579-10588.

66. Jongbloed, J.D.H., Grieger, U., Antelmann, H., Hecker, M., Nijland, R., Bron, S.,van Dijl, J.M. (2004) Two minimal Tat translocases in Bacillus. Mol. Microbiol., 54 (5), 1319-1325.

67. Sturm, A., Schierhorn, A., Lindenstrauss, U., Lilie, H.,Brüser, T. (2006) YcdB from Escherichia coli reveals a novel class of Tat-dependently translocated hemoproteins. J. Biol. Chem., 281 (20), 13972-13978.

68. Yoshida, T.,Sugano, Y. (2015) A structural and functional perspective of DyP-type peroxidase family. Archives of Biochemistry and Biophysics, 574, 49-55.

69. Sugano, Y., Muramatsu, R., Ichiyanagi, A., Sato, T.,Shoda, M. (2007) DyP, a unique dye-decolorizing peroxidase, represents a novel heme peroxidase family: ASP171 replaces the distal histidine of classical peroxidases. J. Biol. Chem., 282 (50), 36652-36658.

70. Singh, R., Grigg, J.C., Armstrong, Z., Murphy, M.E.P.,Eltis, L.D. (2012) Distal Heme Pocket Residues of B-type Dye-decolorizing Peroxidase: ARGININE BUT NOT ASPARTATE IS ESSENTIAL FOR PEROXIDASE ACTIVITY. J. Biol. Chem., 287 (13), 10623-10630.

71. Liu, X., Du, Q., Wang, Z., Zhu, D., Huang, Y., Li, N., Wei, T., Xu, S.,Gu, L. (2011) Crystal structure and biochemical features of EfeB/YcdB from Escherichia coli 0157: ASP235 plays divergent roles in different enzyme-catalyzed processes. J. Biol. Chem., 286 (17), 14922-14931.

72. Pfanzagl, V., Nys, K., Bellei, M., Michlits, H., Mlynek, G., Battistuzzi, G., Djinovic-Carugo, K., Van Doorslaer, S., Furtmüller, P.G., Hofbauer, S.,Obinger, C. (2018) Roles of distal aspartate and arginine of B-class dyedecolorizing peroxidase in heterolytic hydrogen peroxide cleavage. J. Biol. Chem., 293 (38), 14823-14838.

73. Johjima, T., Ohkuma, M.,Kudo, T. (2003) Isolation and cDNA cloning of novel hydrogen peroxide-dependent phenol oxidase from the basidiomycete Termitomyces albuminosus. Appl. Microbiol. Biotechnol., 61 (3), 220-225. 
74. Li, J., Liu, C., Li, B., Yuan, H., Yang, J.,Zheng, B. (2012) Identification and molecular characterization of a novel DyP-type peroxidase from Pseudomonas aeruginosa PKE117. Appl. Biochem. Biotechnol., 166 (3), 774-785.

75. Zubieta, C., Krishna, S.S., Kapoor, M., Kozbial, P., McMullan, D., Axelrod, H.L., Miller, M.D., Abdubek, P., Ambing, E., Astakhova, T., Carlton, D., Chiu, H.-J., Clayton, T., Deller, M.C., Duan, L., Elsliger, M.-A., Feuerhelm, J., Grzechnik, S.K., Hale, J., Hampton, E., Han, G.W., Jaroszewski, L., Jin, K.K., Klock, H.E., Knuth, M.W., Kumar, A., Marciano, D., Morse, A.T., Nigoghossian, E., Okach, L., Oommachen, S., Reyes, R., Rife, C.L., Schimmel, P., van den Bedem, H., Weekes, D., White, A., Xu, Q., Hodgson, K.O., Wooley, J., Deacon, A.M., Godzik, A., Lesley, S.A.,Wilson, I.A. (2007) Crystal structures of two novel dye-decolorizing peroxidases reveal a beta-barrel fold with a conserved heme-binding motif. Proteins, 69 (2), 223-233.

76. Ogola, H.J.O., Kamiike, T., Hashimoto, N., Ashida, H., Ishikawa, T., Shibata, H.,Sawa, Y. (2009) Molecular Characterization of a Novel Peroxidase from the Cyanobacterium Anabaena sp. Strain PCC 7120. Applied and Environmental Microbiology, 75 (23), 7509-7518.

77. Shrestha, R., Chen, X., Ramyar, K.X., Hayati, Z., Carlson, E.A., Bossmann, S.H., Song, L., Geisbrecht, B.V.,Li, P. (2016) Identification of Surface-Exposed Protein Radicals and A Substrate Oxidation Site in A-Class DyeDecolorizing Peroxidase from Thermomonospora curvata. ACS Catal., 6 (12), 8036-8047.

78. Habib, M.H., Rozeboom, H.J.,Fraaije, M.W. (2019) Characterization of a New DyP-Peroxidase from the Alkaliphilic Cellulomonad, Cellulomonas bogoriensis. Molecules, 24 (7), 1208.

79. Shrestha, R., Huang, G., Meekins, D.A., Geisbrecht, B.V.,Li, P. (2017) Mechanistic Insights into DyeDecolorizing Peroxidase Revealed by Solvent Isotope and Viscosity Effects. ACS Catal., 7 (9), 6352-6364.

80. Uchida, T., Sasaki, M., Tanaka, Y.,Ishimori, K. (2015) A Dye-Decolorizing Peroxidase from Vibrio cholerae. Biochemistry, 54 (43), 6610-6621.

81. Singh, R., Grigg, J.C., Qin, W., Kadla, J.F., Murphy, M.E.P.,Eltis, L.D. (2013) Improved Manganese-Oxidizing Activity of DypB, a Peroxidase from a Lignolytic Bacterium. ACS Chem. Biol., 8 (4), 700-706.

82. Roberts, J.N., Singh, R., Grigg, J.C., Murphy, M.E.P., Bugg, T.D.H.,Eltis, L.D. (2011) Characterization of DyeDecolorizing Peroxidases from Rhodococcus jostii RHA1. Biochemistry, 50 (23), 5108-5119.

83. Yoshida, T., Ogola, H.J.O., Amano, Y., Hisabori, T., Ashida, H., Sawa, Y., Tsuge, H.,Sugano, Y. (2016) Anabaena sp. DyP-type peroxidase is a tetramer consisting of two asymmetric dimers: Structural Study of AnaPX. Proteins, 84 (1), 31-42.

84. Fernández-Fueyo, E., Davó-Siguero, I., Almendral, D., Linde, D., Baratto, M.C., Pogni, R., Romero, A., Guallar, V.,Martínez, A.T. (2018) Description of a Non-Canonical Mn(II)-Oxidation Site in Peroxidases. ACS Catal., 8 (9), 8386-8395.

85. Linde, D., Cañellas, M., Coscolín, C., Davó-Siguero, I., Romero, A., Lucas, F., Ruiz-Dueñas, F.J., Guallar, V.,Martínez, A.T. (2016) Asymmetric sulfoxidation by engineering the heme pocket of a dye-decolorizing peroxidase. Catal. Sci. Technol., 6 (16), 6277-6285.

86. Linde, D., Pogni, R., Cañellas, M., Lucas, F., Guallar, V., Baratto, M.C., Sinicropi, A., Sáez-Jiménez, V., Coscolín, C., Romero, A., Medrano, F.J., Ruiz-Dueñas, F.J.,Martínez, A.T. (2015) Catalytic surface radical in dyedecolorizing peroxidase: a computational, spectroscopic and site-directed mutagenesis study. Biochemical Journal, 466 (2), 253-262.

87. Strittmatter, E., Serrer, K., Liers, C., Ullrich, R., Hofrichter, M., Piontek, K., Schleicher, E.,Plattner, D.A. (2015) The toolbox of Auricularia auricula-judae dye-decolorizing peroxidase - Identification of three new potential substrate-interaction sites. Archives of Biochemistry and Biophysics, 574, 75-85.

88. Strittmatter, E., Wachter, S., Liers, C., Ullrich, R., Hofrichter, M., Plattner, D.A.,Piontek, K. (2013) Radical formation on a conserved tyrosine residue is crucial for DyP activity. Arch. Biochem. Biophys., 537 (2), 161167.

89. Yoshida, T., Tsuge, H., Hisabori, T.,Sugano, Y. (2012) Crystal structures of dye-decolorizing peroxidase with ascorbic acid and 2,6-dimethoxyphenol. FEBS Letters, 586 (24), 4351-4356.

90. Yoshida, T., Tsuge, H., Konno, H., Hisabori, T.,Sugano, Y. (2011) The catalytic mechanism of dye-decolorizing peroxidase DyP may require the swinging movement of an aspartic acid residue. FEBS J., 278 (13), 23872394. 
91. Strittmatter, E., Liers, C., Ullrich, R., Wachter, S., Hofrichter, M., Plattner, D.A.,Piontek, K. (2013) First Crystal Structure of a Fungal High-redox Potential Dye-decolorizing Peroxidase: SUBSTRATE INTERACTION SITES AND LONG-RANGE ELECTRON TRANSFER. J. Biol. Chem., 288 (6), 4095-4102.

92. Tonin, F., Vignali, E., Pollegioni, L., D’Arrigo, P.,Rosini, E. (2017) A novel, simple screening method for investigating the properties of lignin oxidative activity. Enzyme Microb. Technol., 96, 143-150.

93. Rahmanpour, R.,Bugg, T.D.H. (2015) Characterisation of Dyp-type peroxidases from Pseudomonas fluorescens Pf-5: Oxidation of $\mathrm{Mn}(\mathrm{II})$ and polymeric lignin by Dyp1B. Archives of Biochemistry and Biophysics, 574, 93-98.

94. Qin, X., Sun, X., Huang, H., Bai, Y., Wang, Y., Luo, H., Yao, B., Zhang, X.,Su, X. (2017) Oxidation of a nonphenolic lignin model compound by two Irpex lacteus manganese peroxidases: evidence for implication of carboxylate and radicals. Biotechnol Biofuels, 10 (1), 103.

95. Yang, C., Yue, F., Cui, Y., Xu, Y., Shan, Y., Liu, B., Zhou, Y.,Lü, X. (2018) Biodegradation of lignin by Pseudomonas sp. Q18 and the characterization of a novel bacterial DyP-type peroxidase. $J$ Ind Microbiol Biotechnol, 45 (10), 913-927.

96. Sugawara, K., Igeta, E., Amano, Y., Hyuga, M.,Sugano, Y. (2019) Degradation of antifungal anthraquinone compounds is a probable physiological role of DyP secreted by Bjerkandera adusta. AMB Expr, 9 (1), 56.

97. Lin, Y. (2019) Rational design of heme enzymes for biodegradation of pollutants toward a green future. Biotechnology and Applied Biochemistry, bab.1788. 
Figures

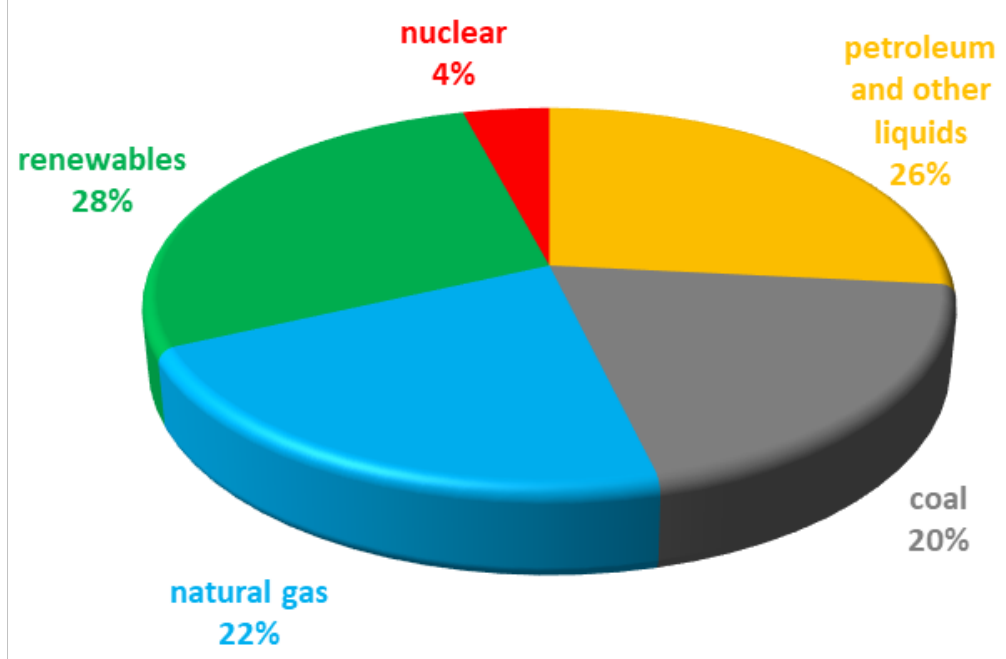

Figure 1 Projections of world energy consumption in 2050 classified by source 


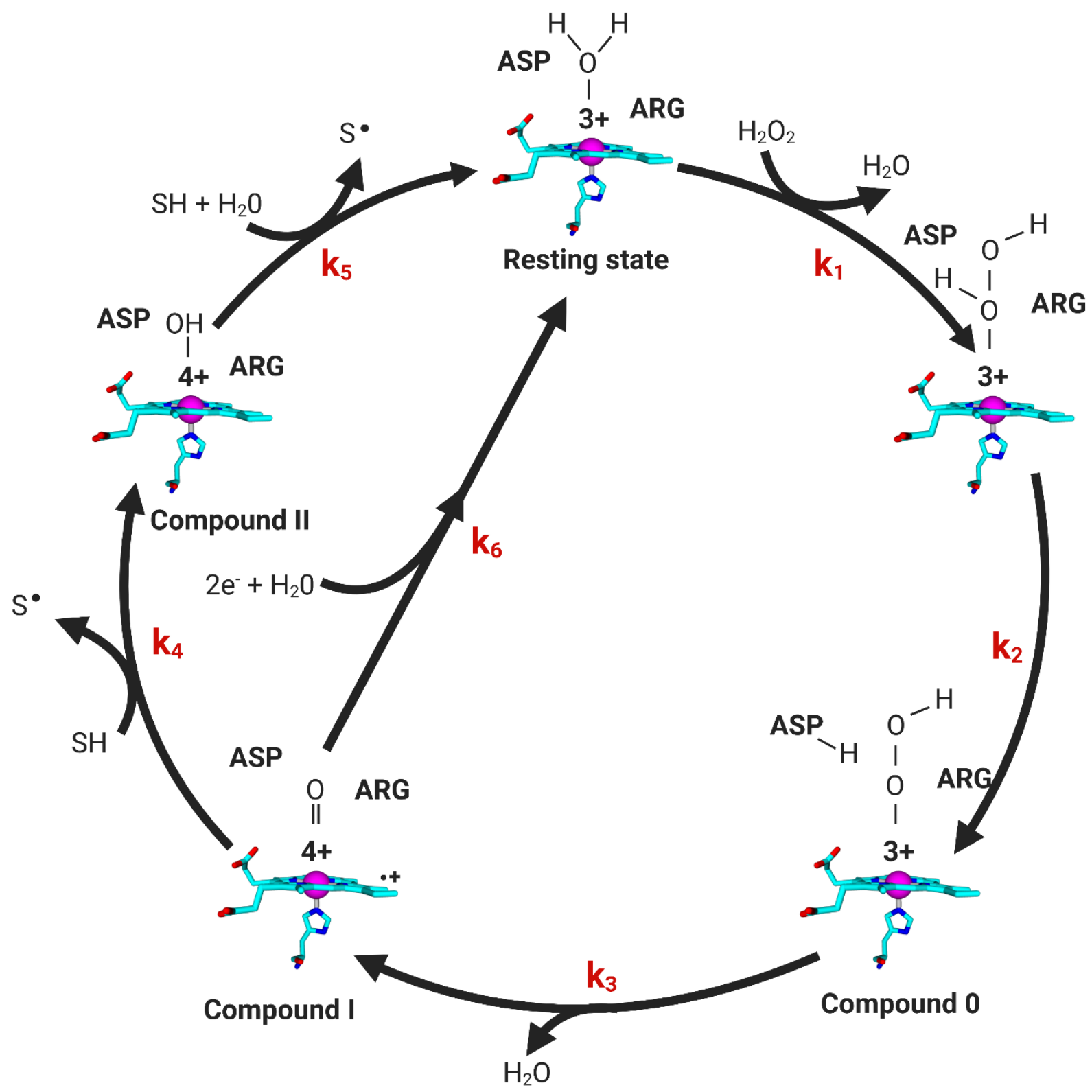

Figure 2 Detailed catalytic cycle of dye-decolorizing peroxidases. Resting state Fe(III) binds $\mathrm{H}_{2} \mathrm{O}_{2}$. Deprotonation of $\mathrm{H}_{2} \mathrm{O}_{2}$ by aspartic acid leads to the formation of Compound 0 . Compound I is formed after heterolytic cleavage of dioxygen resulting in the highly reactive Fe(IV) species. Compound I can either decay into Compound II receiving one electron from a suitable substrate yielding one molecule of radical product or directly to resting state $\mathrm{Fe}(\mathrm{III})$ 
when 2 electrons are provided by the substrate. Compound II decays into Fe(III) resting state yielding a second radical product molecule. 


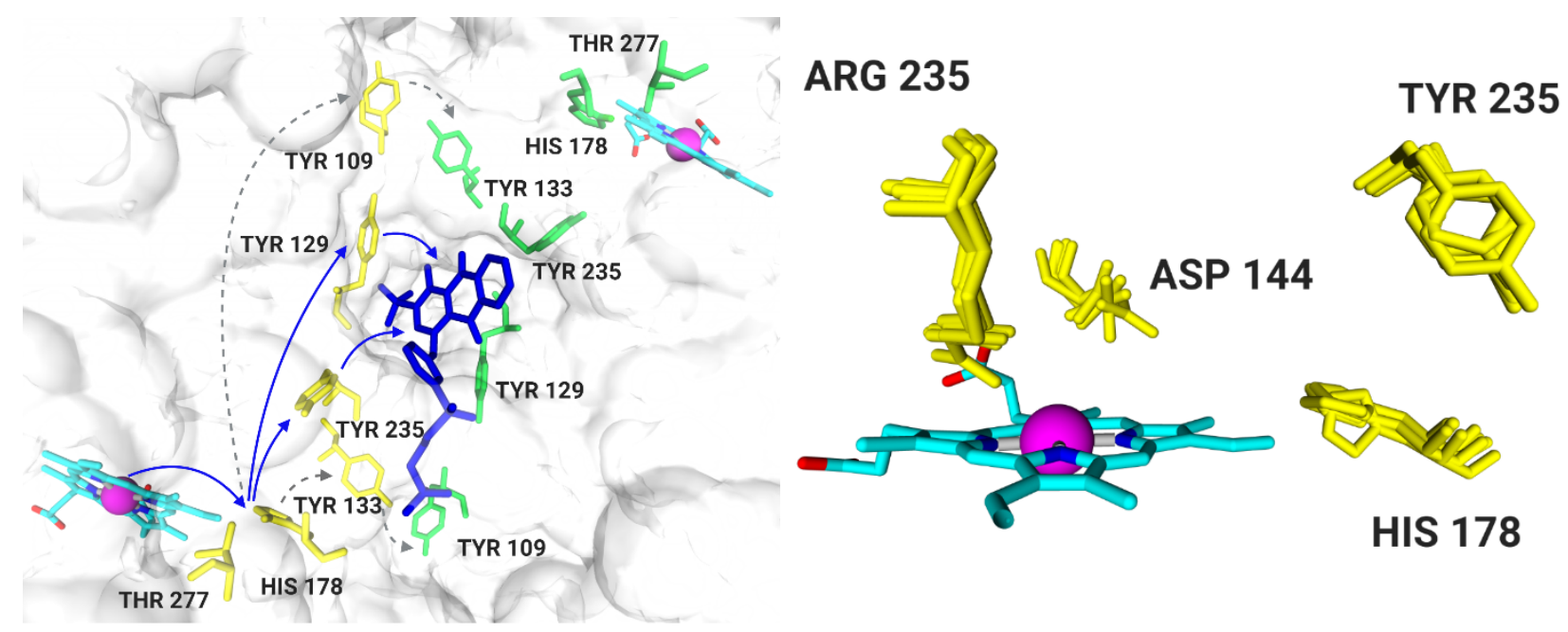

Figure 3. Radical transfer pathways. A) Postulated pathway for Vibrio Cholerae DypB protein dimer. The radical is generated by the heme iron and is transferred to His 178. In acidic conditions His 178 transfers the radical to Tyr 129 or Tyr 235 resulting in the attack of the substrate molecule. In alkaline conditions His 178 transfers the radical to Tyr 133 or Tyr 109 that by transferring the radical to the Tyr residues at the surface result in covalent dimerization. Substrate molecule and productive pathways are shown in blue, grey dashed arrows indicate unproductive pathways. B) Structural alignment showing conserved active site residues of Vibrio Cholerae DypB (PDB ID 5de0) overlayed on representative members of Class B DyPs. PDB IDs: 6fks, 5vj0, 3qhr, 2hag. All residue are conserved except for Rhodococcus Jostii (3qhr) where the tyrosine is replaced by a phenylalanine. 


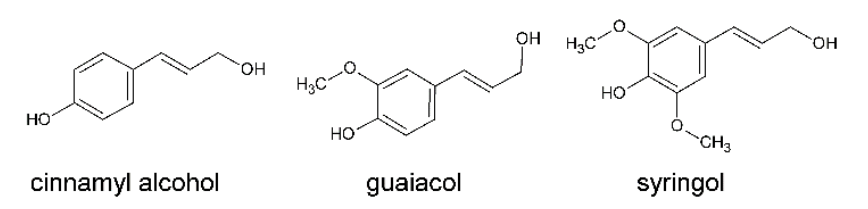

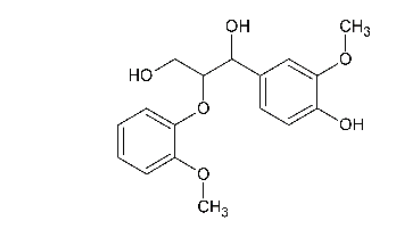

guaiacyl-glycerol- $\beta$-guaiacyl-ether

benzyl-phenyl-ether

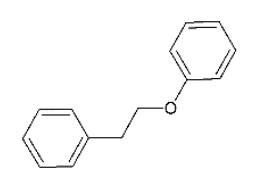

phenethyl-phenyl-ether

diphenyl-ether
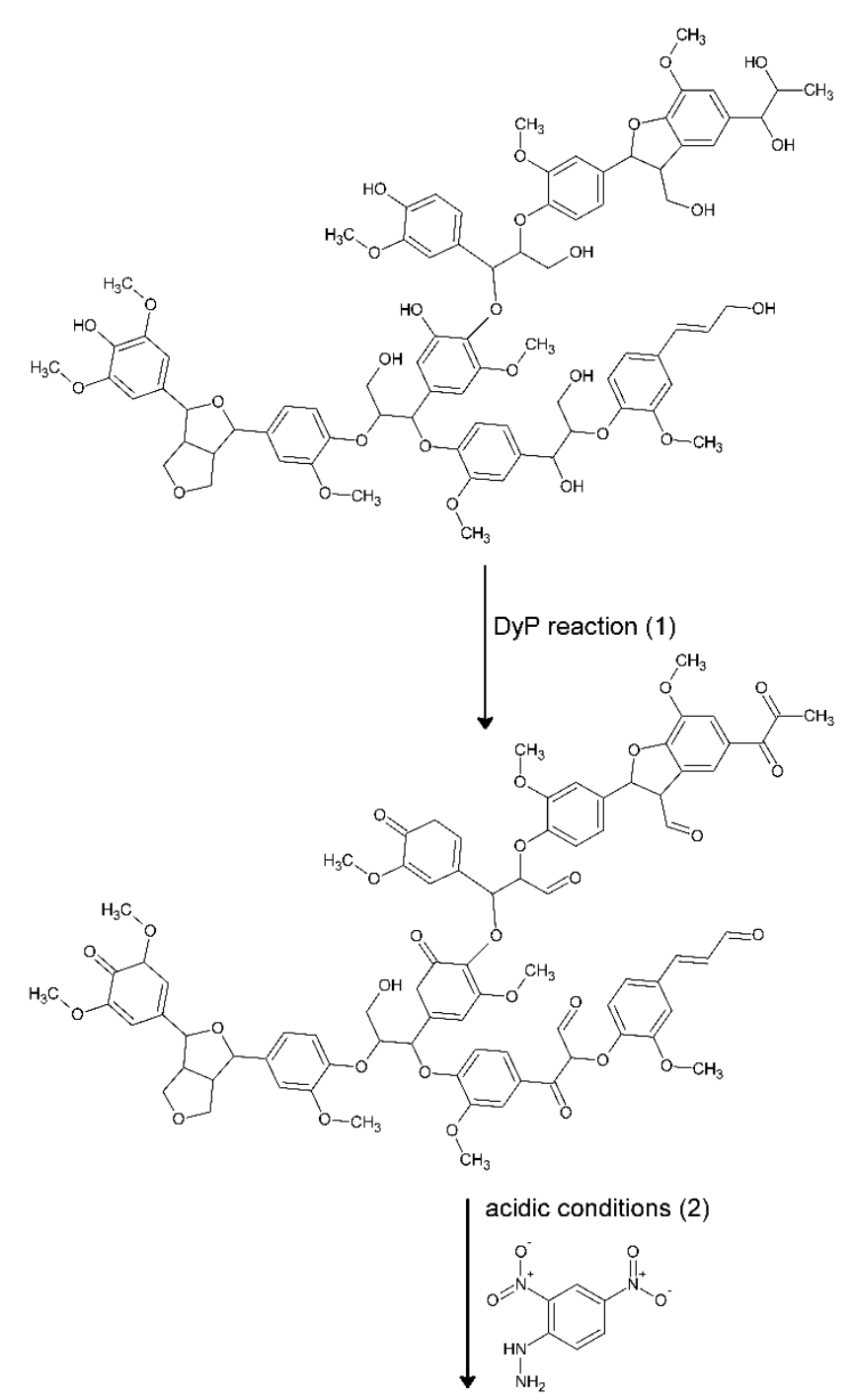

)
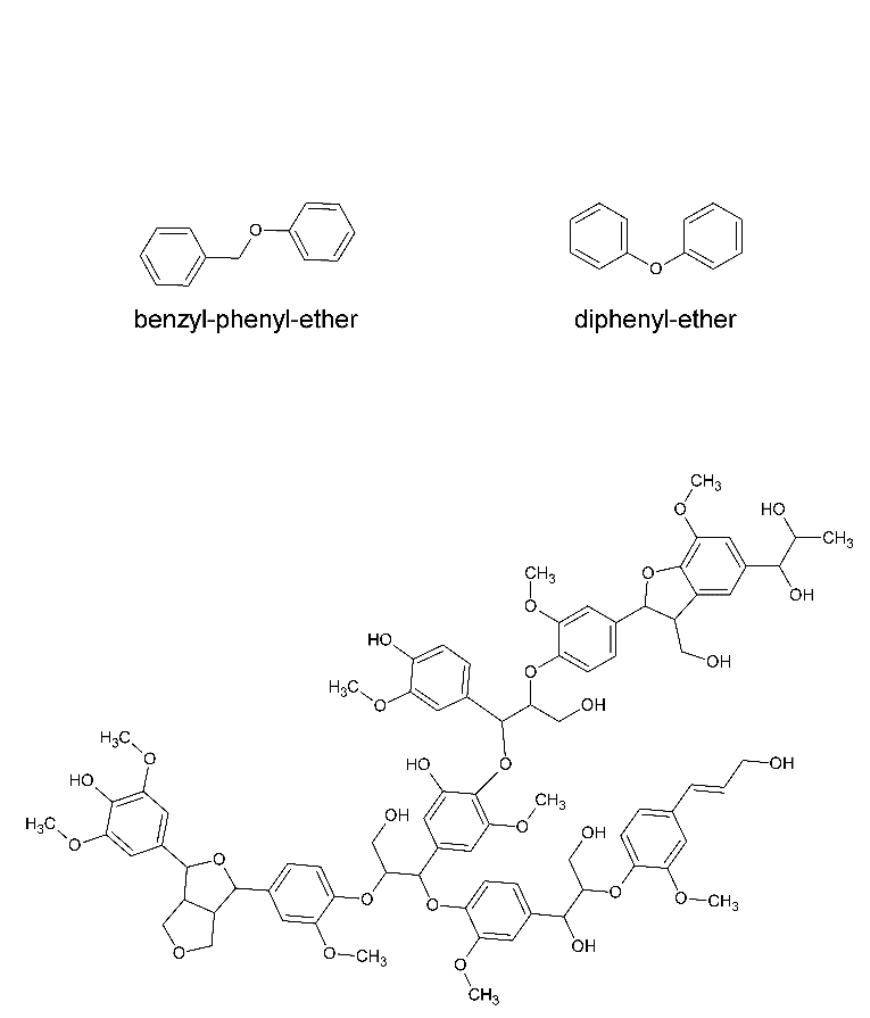

organosolv lignin

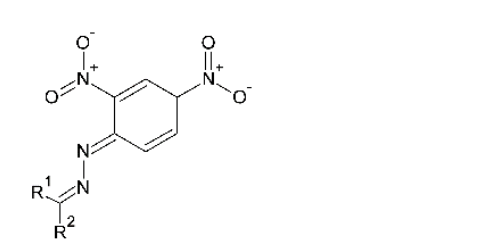

basic conditions (3)

Figure 4. A) Constituents of lignin with increasing level of complexity. Monomeric structures: cinnamyl alcohol, guaiacol and syringol. Dimeric model compounds: guaiacylglycerol- $\beta$-guaiacyl-ether, phenethyl-phenyl-ether, benzyl-phenyl-ether; Polymeric structure: organosolv lignin. B) Colorimetric screening assay for investigating lignin oxidative 
activity. [92] In the first step the enzymatic reaction in the presence of DyP peroxidase (or suitable enzymes) is carried out. In the second step 2,4-dinitrophenylhydrazine reacts with the carbonyl groups generated by enzymatic oxidation in acidic conditions yielding a dinitrophenylhydrazone derivative that in basic conditions (step 3) can be easily detected at $450 \mathrm{~nm}$. 


\section{Tables}

Table 1 Crystal structures of DyP peroxidases

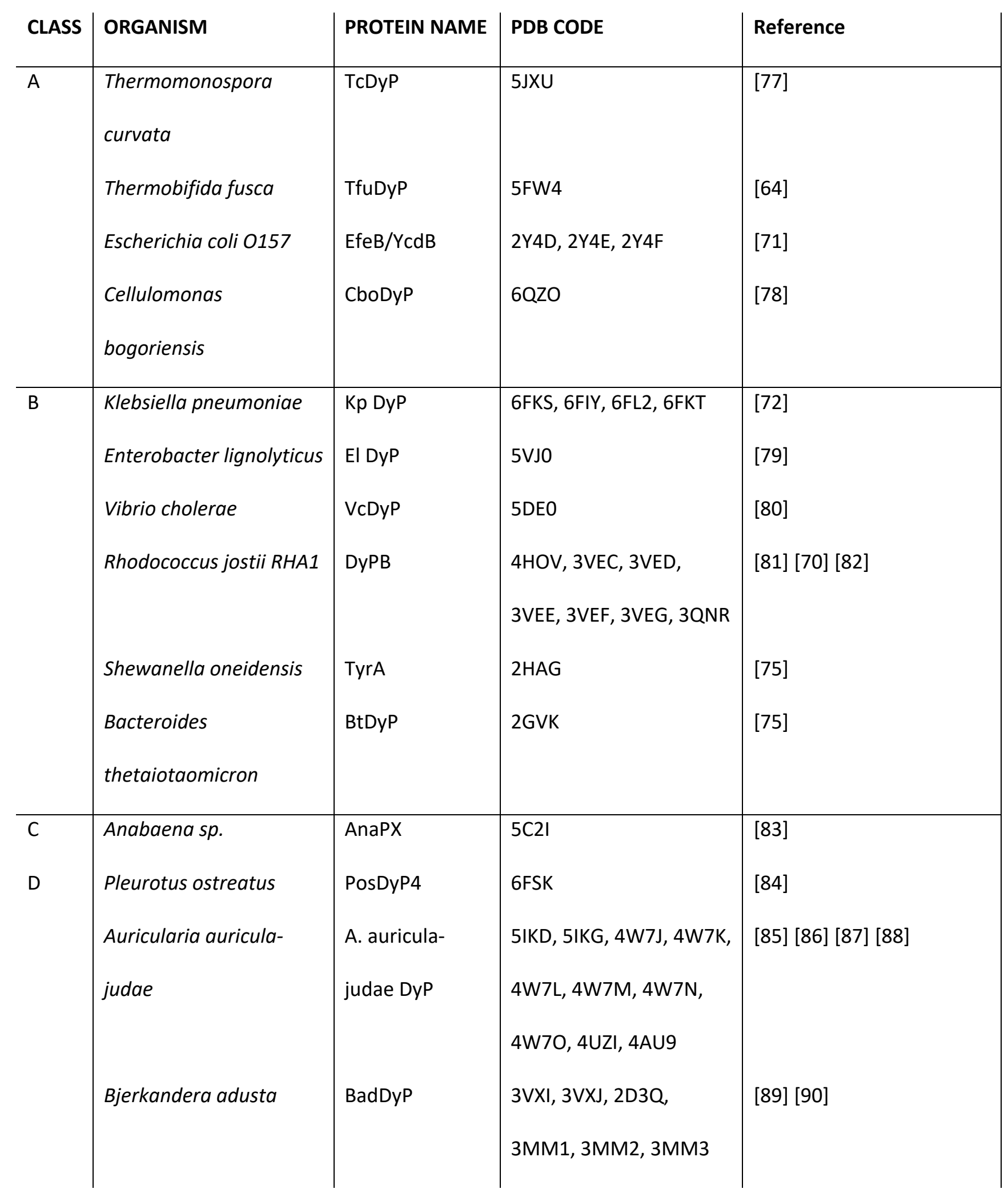

